\title{
Validation of multiple equations for estimating low-density lipoprotein cholesterol levels in Korean adults
}

\author{
Rihwa Choi ${ }^{1,2}$ (D), Mi-Jung Park', Youngju Oh¹, Sung Ho Kim', Sang Gon Lee ${ }^{1 *}$ (D) and Eun Hee Lee ${ }^{1 *}$ (D)
}

\begin{abstract}
Background: Limited data are available for validation of low-density lipoprotein cholesterol (LDL) calculation $\left(L D L_{c a l}\right)$ in the adult Korean population. The aim of this study was to develop and validate a new equation for $L D L_{c a l}$ and to compare it with previous such equations in a Korean population.
\end{abstract}

Methods: $A$ new equation for $L D L_{c a l}$ was developed $\left(L D L_{C h o i}\right)$. $L D L_{C h o i}$ and 11 other previously published equations were applied and compared with directly measured $L D L$ concentration $\left(L D L_{\text {direct }}\right)$ in a development cohort (population 1), an independent validation cohort in the same laboratory (population 2), and the Korea National Health and Nutrition Examination Survey 2017 cohort (population 3).

Results: Among the 12 equations, the newly-developed equation $\left(L D L_{C h o i}=\right.$ total cholesterol $-0.87 \times$ high-density lipoprotein cholesterol $-0.13 \times$ triglycerides) had the highest intraclass correlation coefficient (ICC) and the lowest mean systemic difference and median absolute percentage error in populations 1 and 2 but not in population 3. Subgroup analysis showed good agreement between $L D L_{C h o i}$ and $L D L_{\text {direct }}(I C C>0.75)$ in population 2, whose $\mathrm{LDL}_{\text {direct }}<70 \mathrm{mg} / \mathrm{dL}$. For samples with high triglycerides ( $>400 \mathrm{mg} / \mathrm{dL}$ ), equation accuracy varied. Categorization concordance according to the National Cholesterol Education Program Adult Treatment Panel III criteria with the other 11 equations were less than 80\%; that of $L D L_{\text {Choi }}$ was 87.6 and 87.4\% in populations 1 and 2, respectively.

Conclusions: Accuracy of 12 equations for $L D L_{c a l}$ varied by cohort and subgroup based on $L D L_{\text {direct }}$ and triglycerides. A laboratory-specific equation for $L D L_{c a l}$ and/or $L D L_{\text {direct }}$ may be needed for accurate evaluation of $L D L$ status.

Keywords: Low-density lipoprotein cholesterol, Friedwald equation, Calculated low-density lipoprotein, Martin/Hopkins equation, National Cholesterol Education Program, Korea

\section{Introduction}

Low-density lipoprotein cholesterol (LDL) is a wellknown risk factor and therapeutic target for atherosclerotic disease $[1,2]$. In patients at high cardiovascular risk due to dyslipidemia, low-density lipoprotein cholesterol (LDL) reduction is recommended as the primary treatment goal, with statins as first-line therapy in national

\footnotetext{
* Correspondence: sglee@gclabs.co.kr; ehlee@gclabs.co.kr

'Department of Laboratory Medicine, Green Cross Laboratories, 107, Ihyeonro 30 beon-gil, Giheng-gu, Yongin-Si, Gyeonggi-do, Republic of Korea Full list of author information is available at the end of the article
}

and international clinical practice guidelines $[3,4]$. LDL can be measured directly ( $\left.\mathrm{LDL}_{\text {direct }}\right)$ with several methods $[5,6]$. The accepted gold-standard method for $\mathrm{LDL}$ measurement is labor-intensive, time-consuming, and expensive $\beta$-quantification after ultracentrifugation [7]. Instead, direct homogeneous assays for LDL measurement have been widely used and showed reasonable accuracy and precision compared with the reference method [5, 6]. Meanwhile, LDL is often calculated $\left(\mathrm{LDL}_{\mathrm{cal}}\right)$ from a lipid profile test that includes measurement

(c) The Author(s). 2021 Open Access This article is licensed under a Creative Commons Attribution 4.0 International License, which permits use, sharing, adaptation, distribution and reproduction in any medium or format, as long as you give appropriate credit to the original author(s) and the source, provide a link to the Creative Commons licence, and indicate if changes were made. The images or other third party material in this article are included in the article's Creative Commons licence, unless indicated otherwise in a credit line to the material. If material is not included in the article's Creative Commons licence and your intended use is not permitted by statutory regulation or exceeds the permitted use, you will need to obtain permission directly from the copyright holder. To view a copy of this licence, visit http://creativecommons.org/licenses/by/4.0/ The Creative Commons Public Domain Dedication waiver (http://creativecommons.org/publicdomain/zero/1.0/) applies to the data made available in this article, unless otherwise stated in a credit line to the data. 
of total cholesterol (TC), high-density lipoprotein cholesterol (HDL), and triglycerides (TG) $[3,8]$.

LDL is typically calculated using the Friedewald equation $\left[\mathrm{LDL}_{\text {Friedewald }}=\mathrm{TC}-\mathrm{HDL}-(\mathrm{TG} / 5)\right]$, which was developed based on analysis of 448 patients in 1972 [9]. The Friedewald equation is inaccurate increasingly at TG concentrations from 200 to $400 \mathrm{mg} / \mathrm{dL}$ and is regarded as invalid when at TG level $>400 \mathrm{mg} / \mathrm{dL}[5,10]$. Although several LDL calculation equations have been suggested as alternatives for Friedewald, studies performed in populations using different analytical measurement methods for lipid quantification reported varying equation accuracy $[3,4,8,11-21]$. For example, in the United States, Martin et al. suggested a new equation for LDL estimation $\left(\mathrm{LDL}_{\mathrm{Martin}}\right)$ using an adjustable factor for TG: very-low-density lipoprotein cholesterol (VLDL) ratio based on TG and non-HDL concentration (non-HDL = TC - HDL) stratification based on lipid profiles obtained from 1,350,908 subjects [4]. Martin et al. reported that the overall concordance in guideline risk classification with $\mathrm{LDL}_{\text {direct }}$ was $91.7 \%$ for $\mathrm{LDL}_{\text {Martin }}$ and $85.4 \%$ for $\mathrm{LDL}_{\text {Friede- }}$ wald for patients with TG lower than $400 \mathrm{mg} / \mathrm{dL}$, but the concordance was modest (from 57.8 to $69.8 \%$ ) in patients with $\mathrm{TG} \geq 400 \mathrm{mg} / \mathrm{dL}$ [4]. An indiVidual patient metaanalysis Of statin therapY in At risk Groups: Effects of Rosuvastatin, atorvastatin and simvastatin (VOYAGER) was conceived to compare the efficacy of three statins most commonly used in clinical practice (atorvastatin, rosuvastatin, and simvastatin) using patient meta-analysis to characterize the effect of individual statin agents on lipid levels using individual patient data from pooled clinical studies [22]. The VOYAGER database contains LDL concentrations using $\mathrm{LDL}_{\text {Friedewald }}$ for patients with $\mathrm{TG} \leq$ $400 \mathrm{mg} / \mathrm{dL}$ and $\mathrm{LDL}_{\text {direct }}$ using $\beta$-quantification for those with TG $>400 \mathrm{mg} / \mathrm{dL}$ [22]. However, a recent study from the VOYAGER meta-analysis database aimed to investigate the difference in $\mathrm{LDL}_{\text {cal }}$ when using the $\mathrm{LDL}_{\text {Martin }}$ and $\mathrm{LDL}_{\text {Friedewald }}$ equations reported that $\mathrm{LDL}_{\text {Martin }}$ might not be suitable for patients with $\mathrm{TG} \geq 400 \mathrm{mg} / \mathrm{dL}$ and can result in overestimation of $\mathrm{LDL}_{\text {direct }}$ [13]. Considering that ethnically and ancestrally diverse populations having different allele frequencies of genetic determinants of blood lipids, for which transferable or non-transferable loci might affect lipids in gene-environment interactions [23], validation of accurate clinical applicability for all equations in various ethnic populations is needed $[1,3,13,20,21]$.

In Korea, limited data are available on the accuracy of equations for $\mathrm{LDL}_{\text {cal }}$. Previous studies performed in Korea investigated the accuracy of limited numbers of equations for $\mathrm{LDL}_{\text {cal }}[8,14,18]$. In Korea, $\mathrm{LDL}_{\text {Friedewald }}$ is most commonly used for $\mathrm{LDL}_{\text {cal }}[8,24]$. Therefore, the aim of this study was to evaluate the performance of a new $\mathrm{LDL}$ equation $\left(\mathrm{LDL}_{\mathrm{Choi}}\right)$ along with previous $\mathrm{LDL}$ estimations using 11 equations for LDL calculation in comparison with directly measured LDL in Korean adults to improve understanding of LDL calculations when direct measurement is unavailable. To the best of our knowledge, this study includes the largest number of equations to be validated in a Korean population.

\section{Materials and methods \\ Study subjects}

Clinical lipid profile test results (TC, HDL, TG, and $\mathrm{LDL}_{\text {direct }}$ ) performed between July 4, 2017 and September 5, 2018 in Korean adults (>19 years) from the Green Cross Laboratories information system were reviewed retrospectively. Green Cross Laboratories is a referral clinical laboratory in Korea that provides clinical specimen analysis services including lipid profile tests to clinics and hospitals nationwide. Data obtained between July 4, 2017, and September 5, 2018, were used to develop a new equation for $\mathrm{LDL}$ calculation $\left(\mathrm{LDL}_{\mathrm{Choi}}\right)$ in this study, and data obtained from September 6 to November 30, 2018, were used as a separate data set (population 2, the validation cohort 1) to validate the newly-developed $\mathrm{LDL}_{\mathrm{Choi}}$ equation. Data from the Korea National Health and Nutrition Examination Survey (KNHANES) 2017, a nationwide cross-sectional study regularly conducted by the Division of Chronic Disease Surveillance, Korea Centers for Disease Control and Prevention of the Ministry of Health and Welfare, was independently analyzed (population 3, the validation cohort 2) to evaluate generalizability of the 11 previously suggested equations and the $\mathrm{LDL}_{\mathrm{Choi}}$ equation developed in this study. All data were anonymized before analysis. The overall study design is shown in Fig. 1. The data that support the findings of this study are available from the corresponding authors upon reasonable request.

\section{Analytical procedures}

Serum concentrations of TC, TG, HDL, and LDL were measured using enzymatic methods with an automatic analyzer (Cobas 8000 c702, Roche, Mannheim, Germany). LDL was measured using LDL-cholesterol plus 2nd generation reagent on samples between July 4, 2017, and February 4, 2018, and LDL-cholesterol Gen.3 (Roche, Mannheim, Germany) between February 5 and November 30, 2018. TC, TG, and HDL were measured using Cholesterol Gen.2, TRIGL, and HDL-Cholesterol plus 3rd generation, respectively. The accuracy of lipid measurements was assured through the Accuracy Based Lipid Survey proficiency testing program by the College of American Pathologists and by the Lipids Standardization Program by the Centers for Disease Control, USA [25].

For population 3 (validation cohort 2, KNHANES 2017), serum TC, TG, HDL, and LDL were measured using enzymatic methods with an automatic analyzer 


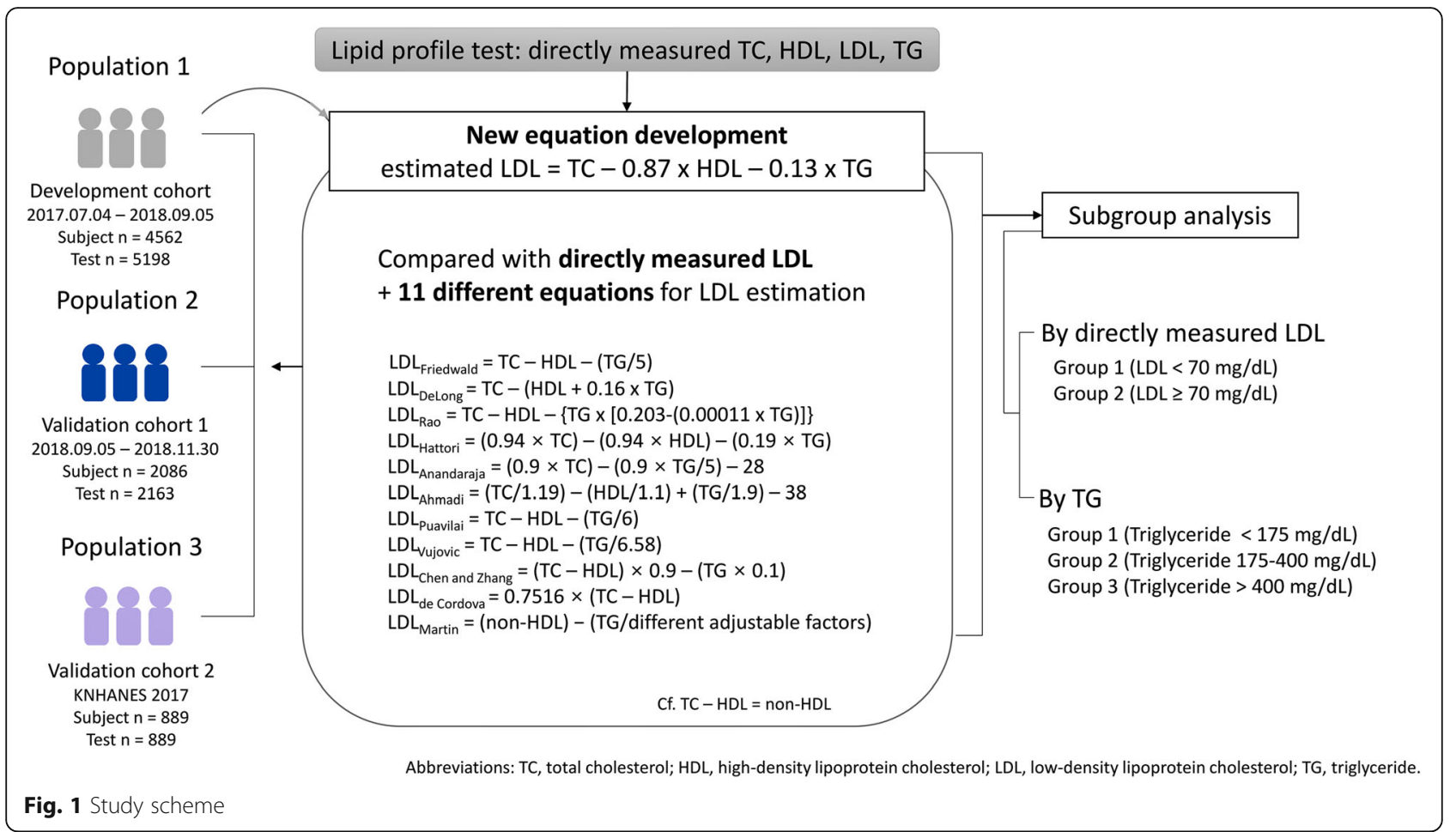

Hitachi 7600-210 (Hitachi, Tokyo, Japan) using PureautoS CHO-N, Pureauto S TG-N, Cholestest N HDL, and Cholestest LDL reagents (Sekisui Medical, Tokyo, Japan), respectively [24].

\section{Selection of equations for calculated LDL}

LDL was calculated using 11 previously published equa-

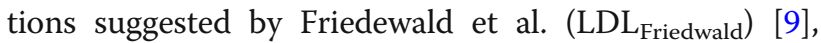
DeLong et al. (LDL $\mathrm{LeLong}_{\text {) }}$ [15], Rao et al. (LDL $\mathrm{Lao}_{\text {Ra }}$ [26], Hattori et al. (LDL $\mathrm{L}_{\text {Hattori }}$ ) [16], Anandaraja et al. (LDL

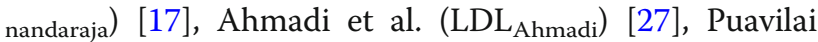
et al. (LDL $\left.L_{\text {Puavilai }}\right)$ [11], Chen and Zhang et al. (LDL Chen and Zhang) [19], Vujovic et al. (LDL Vujovic) [28], de Cordova et al. (LDL de Cordova) [29], and Martin et al. $\left(\mathrm{LDL}_{\text {Martin }}\right)$ [4]. And a new equation ( $\left.\mathrm{LDL}_{\mathrm{Choi}}\right)$ using multiple linear regression analysis of TC, TG, HDL and $\mathrm{LDL}_{\text {direct }}$ values using the development cohort. All 12 of these equations were compared with $\mathrm{LDL}_{\text {direct }}$ measured using a homogenous enzymatic method for development and independent validation cohorts, which including populations of the KNHANES 2017 cohort.

\section{Statistical analysis}

The distribution of continuous variables is described as mean with standard deviation (for normally distributed variables) or as median with interquartile range (for skewed variables) and compared using an independent $\mathrm{t}$ test and Wilcoxon rank sum test, respectively. Categorical variables are reported as observed number and percentage as calculated using the Chi-square test.

Agreement and accuracy of the 12 equations for estimating $\mathrm{LDL}_{\text {cal }}$ were investigated using $\mathrm{LDL}_{\text {direct }}$ as the reference value. The intraclass correlation coefficient (ICC) was calculated to compare the degrees of agreement between the 12 equations and $\mathrm{LDL}_{\text {direct. }}$. The level of agreement was defined according to ICC value; good agreement was when ICC $>0.75$, and moderate agreement was when $0.5<\mathrm{ICC}<0.75$ [18]. Bland-Altman plots were assessed to compare $\mathrm{LDL}_{\text {direct }}$ and multiple equations for $\mathrm{LDL}_{\mathrm{cal}}$.

Subgroup analysis was performed to investigate whether discordant LDL quantification occurs when LDL cholesterol is measured or calculated with different assays, especially in patients with low LDL cholesterol or hypertriglyceridemia [1]. Data were classified into two groups (LDL $<70 \mathrm{mg} / \mathrm{dL}$ in LDL group 1 and $\mathrm{LDL} \geq 70$ $\mathrm{mg} / \mathrm{dL}$ in LDL group 2) for subgroup analysis to investigate the performance of each equation based on LDL concentration. Data were classified into three groups according to serum TG concentration as follows: < 175, 175-400, and $>400 \mathrm{mg} / \mathrm{dL}[5,10]$ for subgroup analysis to investigate the performance of each equation based on TG concentration.

Agreement according to category based on the National Cholesterol Education Program (NCEP) Adult Treatment Panel III (ATP III) between LDL $_{\text {cal }}$ estimated using the 12 equations and $\mathrm{LDL}_{\text {direct }}$ concentration was 
also assessed. Optimal LDL concentration for $<100 \mathrm{mg} /$ $\mathrm{dL}$, above optimal for $100-129 \mathrm{mg} / \mathrm{dL}$, borderline high for $130-159 \mathrm{mg} / \mathrm{dL}$, high for $160-189 \mathrm{mg} / \mathrm{dL}$, and very high for $\geq 190 \mathrm{mg} / \mathrm{dL}$ were applied [30]. Equations for $\mathrm{LDL}_{\text {cal }}$ and NCEP ATP III criteria for each $\mathrm{LDL}_{\text {cal }}$ are provided as online Supplementary Material S1.

Statistical analysis was executed using MedCalc software for Windows, version 19.1.3 (MedCalc Software bv, Ostend, Belgium; https://www.medcalc.org; 2019). Statistical significance was defined as a $P$-value less than 0.05 .

\section{Results}

A total of 5198 lipid profile test results from 4562 Korean adults was obtained between July 4, 2017, and September 5, 2018, and was used to develop a new equation for $\mathrm{LDL}$ calculation $\left(\mathrm{LDL}_{\mathrm{Choi}}\right)$. Using multiple linear regression analysis of the development cohort data with 5198 lipid profile test results, a new equation for estimated $\mathrm{LDL}_{\text {cal }}$ was developed as follows: $\mathrm{LDL}_{\text {Choi }}=$ TC -0.87 x HDL -0.13 x TG. Between September 6 and November 30, 2018, 2163 lipid profile test results from 2086 Korean adults were obtained in the same laboratory and used as a separate data set (population 2, validation cohort 1 ), with which $\mathrm{LDL}_{\text {direct }}$ was measured with a different reagent generation to validate the newly developed $\mathrm{LDL}_{\mathrm{Choi}}$ equation. For another independent validation cohort (population 3, validation cohort 2), a total of 889 lipid profile test results from 889 Korean adults was used. General characteristics and lipid profile test results in the three independent populations in this study are summarized in Table 1 . In the KNHANES 2017 cohort (validation cohort 2, population 3), the proportion of male subjects was greater than that of female subjects, there were no subjects with TG $<175 \mathrm{mg} / \mathrm{dL}$, and there were more patients with $\mathrm{TG}>400 \mathrm{mg} / \mathrm{dL}$ compared to the other cohorts.

Including the newly developed equation ( $\left.\mathrm{LDL}_{\mathrm{Choi}}\right), 12$ equations for $\mathrm{LDL}_{\mathrm{cal}}$ were analyzed. In populations 1 (development cohort) and 2 (validation cohort 1), the mean value of estimated $\mathrm{LDL}_{\mathrm{cal}}$ in total subjects (men and women) showed negative bias in comparison with $\mathrm{LDL}_{\text {direct }}$ except for $\mathrm{LDL}_{\text {Ahmadi }}$ (Supplementary Fig. S1 and Table S1). In population 3 (validation cohort 2, KNHANES 2017), estimated $L^{2} L_{\text {Ahmadi }}$ showed a mean value greater than two times that of $\mathrm{LDL}_{\text {direct. }}$ Because $\mathrm{LDL}_{\mathrm{Rao}}, \mathrm{LDL}_{\mathrm{Ahmadi}}$, and $\mathrm{LDL}_{\text {de Cordova }}$ equations had several outliers with large differences between estimated $\mathrm{LDL}$ and $\mathrm{LDL}_{\text {direct }}$, Bland-Altman plots for only nine of the equations are shown in Fig. 2.

Among the 12 equations for $\mathrm{LDL}_{\text {cal }}$, the newly developed $\mathrm{LDL}_{\mathrm{Choi}}$ equation showed the highest ICC in the development cohort (population 1) and in validation cohort 1 (population 2). However, $\mathrm{LDL}_{\text {DeLong, }} \mathrm{LDL}_{\mathrm{Rao}}$, $\mathrm{LDL}_{\text {Puavilai, }} \mathrm{LDL}_{\text {Chen and }}$ Zhang, $\mathrm{LDL}_{\text {Vujovic }}$, and $\mathrm{LDL}_{\text {Martin }}$ showed a higher ICC than did $\mathrm{LDL}_{\text {Choi }}$ in validation cohort 2 (population 3, KNHANES 2017). All equations except $\mathrm{LDL}_{\text {Ahmadi }}$ showed good agreement with ICC > 0.75 . LDL $_{\text {Choi }}$ showed the lowest mean systemic difference in populations 1 and 2, although other equations showed lower systemic differences than $\mathrm{LDL}_{\mathrm{Choi}}$ in validation cohort 2 (population 3, KNHANES 2017). The limits of agreement with $\mathrm{LDL}_{\text {direct }}$ and $\mathrm{LDL}_{\text {cal }}$ from each equation are summarized in Supplementary Table S2. $\mathrm{LDL}_{\text {Choi }}$ showed the lowest absolute percentage error for $\mathrm{LDL}_{\text {direct }}$ estimation in populations 1 and 2 but not in population 3.

In subgroup analysis according to $\mathrm{LDL}_{\text {direct }}$ concentration, the equations showed variable accuracy in comparison with $\mathrm{LDL}_{\text {direct }}$ (Supplementary Tables S3 to S4 and Supplementary Figs. S2). The top three equations that showed high ICC, low mean systemic differences, or low absolute percentage errors are presented in color. In LDL group 1 ( $\mathrm{LDL}_{\text {direct }}<70 \mathrm{mg} / \mathrm{dL}$ ), no equation showed good agreement $(\mathrm{ICC}>0.75)$ with $\mathrm{LDL}_{\text {direct }}$ except $\mathrm{LDL}_{\text {Choi }}$ in women in population $2(\mathrm{ICC}=0.81)$. Different equations ranked as top three among subgroups. In LDL group $1\left(\mathrm{LDL}_{\text {direct }}<70 \mathrm{mg} / \mathrm{dL}\right)$, the newly developed $\mathrm{LDL}_{\mathrm{Choi}}$ equation was included frequently in the top three equations for ICC, mean systemic differences, and absolute percentage errors in populations 1 and 2 but not in population 3 .

In subgroup analysis according to TG concentration (Supplementary Tables S5 and S6 and Supplementary Fig. S3), all equations except $\mathrm{LDL}_{\text {de }}$ Cordova showed good agreement $(\mathrm{ICC}>0.75)$ with $\mathrm{LDL}_{\text {direct }}$ in TG group 1 (TG $<175 \mathrm{mg} / \mathrm{dL}$ ). In TG group 2 (TG $175-400 \mathrm{mg} / \mathrm{dL}$ ), all equations showed good agreement with $\mathrm{LDL}_{\text {direct }}$ except $\mathrm{LDL}_{\text {Ahmadi }}$ in all three populations. In TG group 3 (TG $>400 \mathrm{mg} / \mathrm{dL}$ ), the $\mathrm{LDL}_{\text {DeLong, }} \mathrm{LDL}_{\text {Vujovic }}, \mathrm{LDL}_{\text {Chen }}$ and Zhang, $\mathrm{LDL}_{\mathrm{Martin}}$, and $\mathrm{LDL}_{\mathrm{Choi}}$ equations showed good agreement with $\mathrm{LDL}_{\text {direct }}$ in all three populations.

Considering median and 95th percentile values of absolute percentage errors, no equations showed values $\leq 12.0 \%$ in all three populations. In subgroup analysis by $\mathrm{LDL}_{\text {direct }}$ concentration, only $\mathrm{LDL}_{\mathrm{Choi}}$ showed median absolute percentage error values $\leq 12.0 \%$ in populations 1 and 2 in LDL group 1 (LDL $<70 \mathrm{mg} / \mathrm{dL}$ ). In subgroup analysis by TG concentration, no equation showed $\leq 12.0 \%$ error for 95 th percentile values of absolute percentage error in TG group 2 (TG $175-400 \mathrm{mg} / \mathrm{dL}$ ) or TG group 3 (TG $>400 \mathrm{mg} / \mathrm{dL})$, while only $\mathrm{LDL}_{\text {Choi }}$ showed $\leq 12.0 \%$ in TG group 1 ( $\mathrm{TG}<175 \mathrm{mg} / \mathrm{dL}$ ) in populations 1 and 2.

Overall concordant categorization agreement according to the NCEP ATP III between $\mathrm{LDL}_{\text {cal }}$ estimated using the 12 equations and $\mathrm{LDL}_{\text {direct }}$ concentration is summarized in Fig. 3. The concordance rate varied among equations for $\mathrm{LDL}_{\mathrm{cal}}$. Categorization concordance 


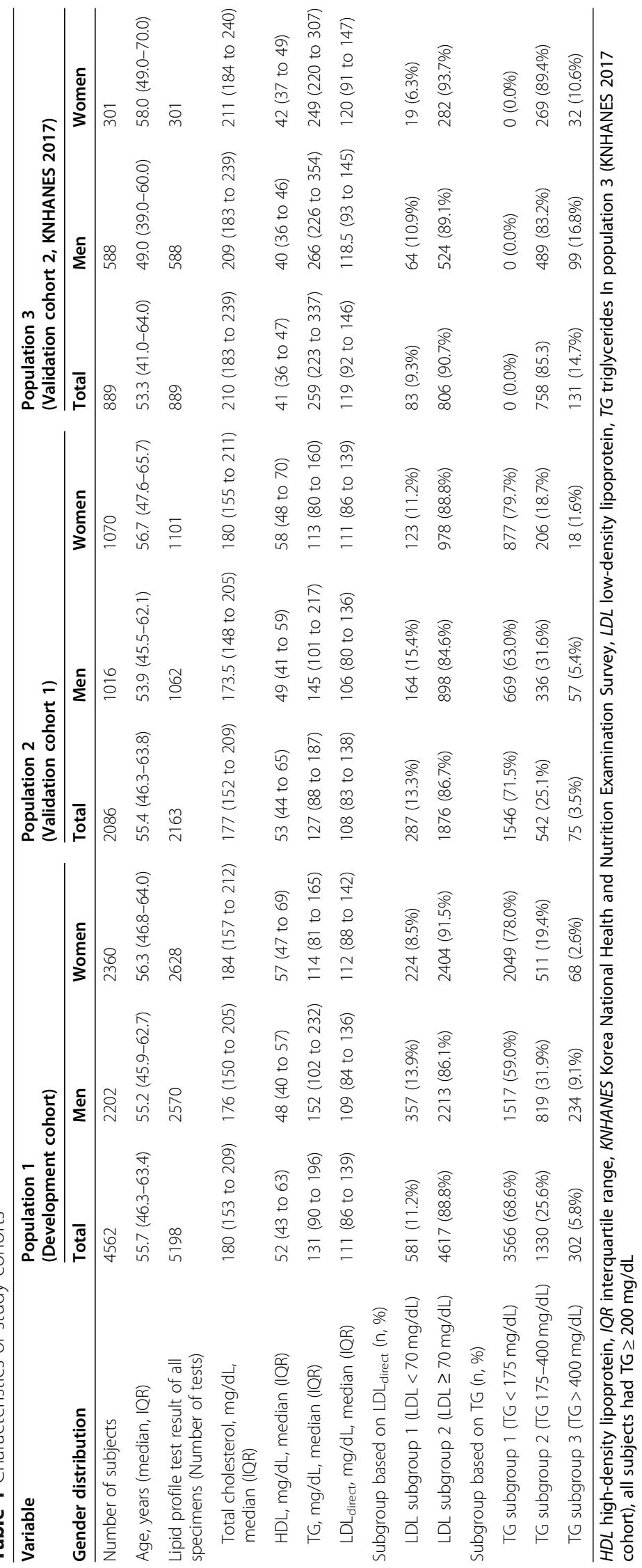




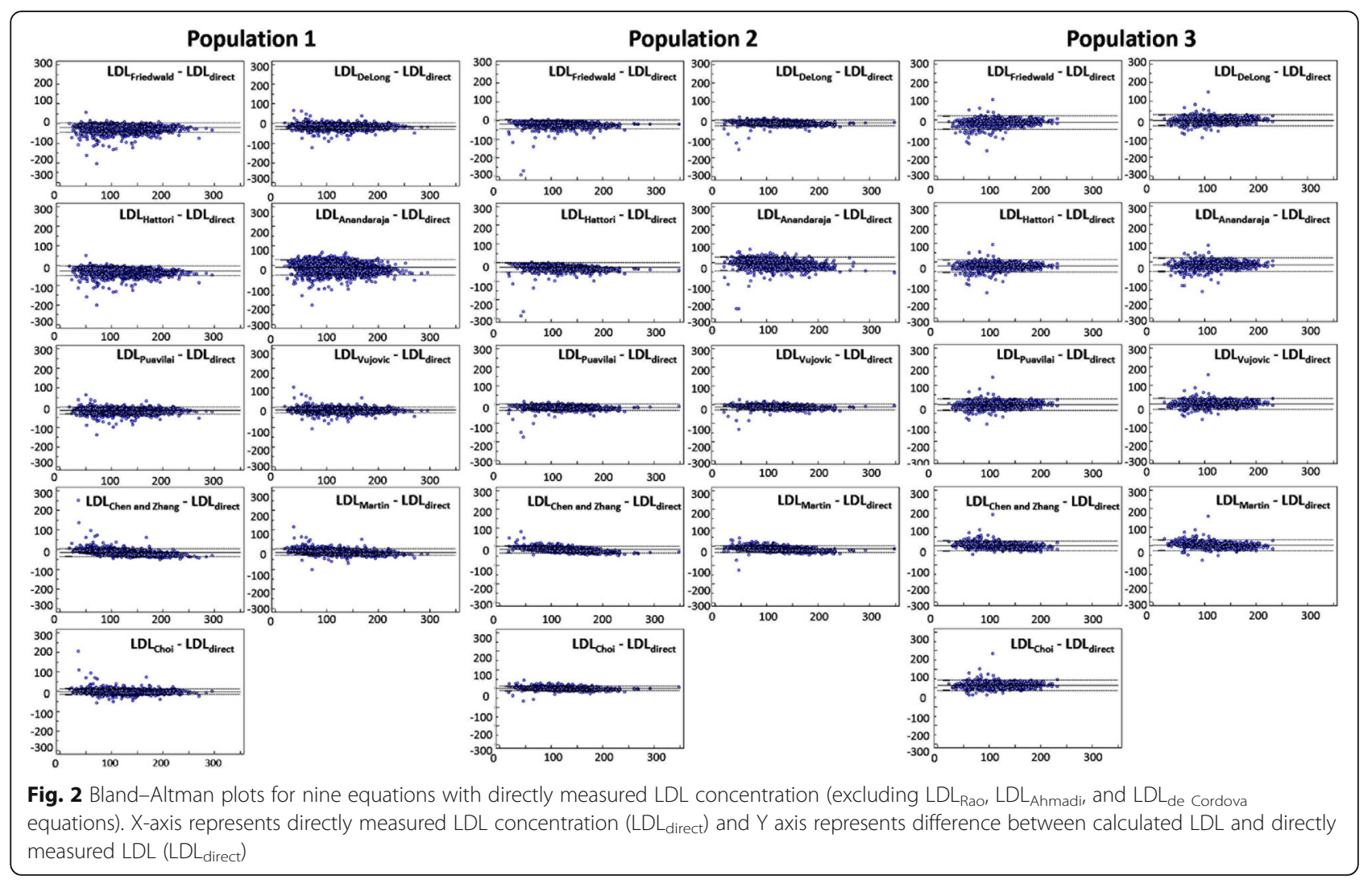

according to the NCEP criteria in the other 11 equations was less than $80 \%$ in all three populations. However, $\mathrm{LDL}_{\text {Choi }}$ showed the highest concordance with $\mathrm{LDL}_{\text {direct }}$ $(86.8-88.0 \%)$ in populations 1 and 2, followed by $\mathrm{LDL}_{\mathrm{Vu}-}$ jovic In population $3, \mathrm{LDL}_{\mathrm{Choi}}$ overestimated $38.8 \%$ of results, while the other equations except for $\mathrm{LDL}_{\text {Hattori }}$ showed higher concordance than $\mathrm{LDL}_{\text {Choi }}$.

\section{Discussion}

In this study, a new equation ( $\mathrm{LDL}_{\mathrm{Choi}}$ ) for LDL estimation is developed and validated in agreement and accuracy with $\mathrm{LDL}_{\text {direct }}$ as the reference value using two independent cohorts in comparison with 11 equations established in previous studies in a Korean population. Although several studies have been reported to validate several of the 11 equations in the Korean population, to the best of our knowledge, this study includes the largest number of concurrent equations for validation of estimating $\mathrm{LDL}_{\text {cal }}$.

The $\mathrm{LDL}_{\text {Choi }}$ showed good agreement with $\mathrm{LDL}_{\text {direct }}$ in populations 1 and 2, which contained lipid profile data from different periods using different generations of reagents in the same laboratory. However, in population 3 data from KNHANES 2017, all other equations showed higher values for ICCs and lower values for systemic differences and absolute percentage errors. Different equations showed different performance among the three populations in this study. These findings might be due to various factors in measurement of $\mathrm{LDL}_{\text {direct }}$, including analytical methods with use of different reagents and instruments as well as different ethnicities and populations with various health conditions [8]. These findings suggest that laboratory-specific equations would provide more accurate values of estimated $\mathrm{LDL}_{\text {cal }}$ rather than use of $\mathrm{LDL}_{\text {Friedwald. }}$.

In the era of personalized medicine, patient-specific risk estimation is important for health care [3]. In this study, categorization concordance according to the NCEP criteria in the previously developed 11 equations was less than $80 \%$ in all three populations. These findings suggest that $\mathrm{LDL}_{\text {cal }}$ concentration was under- or over-estimated for more than $20 \%$ of patients. Previous studies regarding evaluation and validation of various equations for $\mathrm{LDL}_{\mathrm{cal}}$ estimation usually included specimen results with TG concentration $<400 \mathrm{mg} / \mathrm{dL}$ based on the limitation of accuracy for the $\mathrm{LDL}_{\text {Friedewald }}$ equation [1]. In the present study, the accuracy of 12 equations of $\mathrm{LDL}_{\text {cal }}$ was evaluated using 511 test results with $>400 \mathrm{TG} \mathrm{mg} / \mathrm{dL}$. Although the highest concordance rate according to NCEP ATP III criteria was observed as 81.3\% in population 1 and $75.5 \%$ in population 2 for LDL $_{\text {Choi }}$ in TG subgroup 3 (TG $>400 \mathrm{mg} / \mathrm{dL}$ ), the concordance according to NCEP ATP III criteria was 71.0\% for $\mathrm{LDL}_{\text {Friedwald }}, 55.7 \%$ for the newly developed $\mathrm{LDL}_{\mathrm{Choi}}$ 


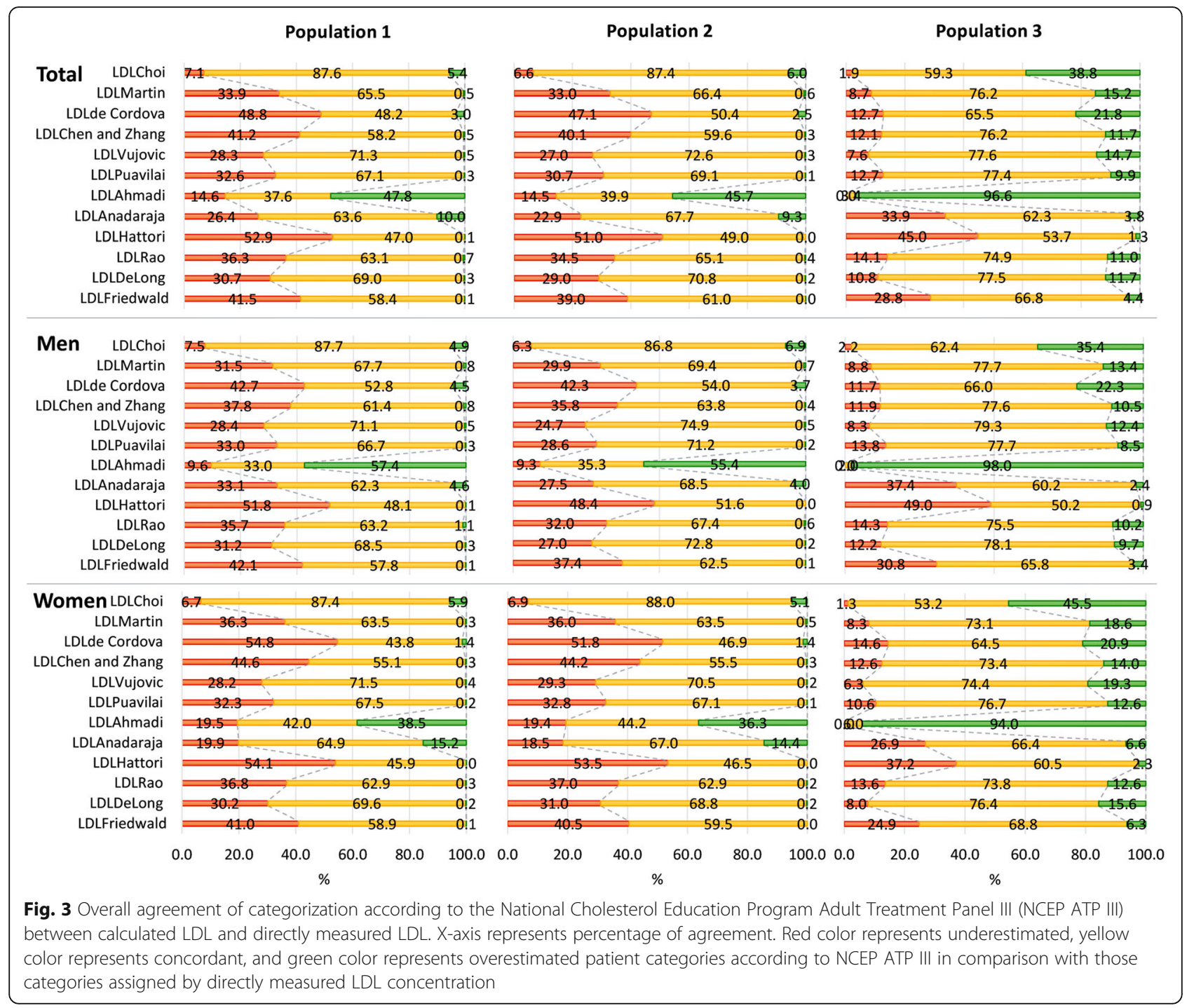

equation, $77.1 \%$ for $\mathrm{LDL}_{\text {Vujovic }}$ and $76.3 \%$ for $\mathrm{LDL}_{\text {Puavilai }}$ in population 3 for TG subgroup 3 ( $\mathrm{TG}>400 \mathrm{mg} / \mathrm{dL}$ ). These findings confirmed the validation of equations for estimated $\mathrm{LDL}_{\text {cal }}[1,14,18]$. Considering that the NCEP ATP III criteria could affect the management plan, accurate assignment of patient categorization with accurate LDL estimation is needed [4].

According to NCEP criteria, the total error of LDL measurements should be within $12 \%$ of the true value [7]. In this study, although median values of absolute percentage errors were $\leq 12 \%$ in some equations, when considering both the median and 95th percentile values of absolute percentage errors $\leq 12 \%$, no equations met these requirements. Only the $\mathrm{LDL}_{\mathrm{Choi}}$ equation met the median and 95th percentile values of absolute percentage errors $\leq 12 \%$ in specimens with $\mathrm{LDL} \geq 70 \mathrm{mg} / \mathrm{dL}$ in the subgroup analysis for LDL concentration groups and in specimens with $\mathrm{TG}<175 \mathrm{mg} / \mathrm{dL}$ in the subgroup analysis for TG concentration in populations 1 and 2 . This finding confirmed that previous estimations of LDL might not be applicable in samples with low LDL or high TG concentration, and $\mathrm{LDL}_{\text {direct }}$ is needed for accurate assessment of LDL concentration [31, 32].

\section{Comparisons with other equations}

A recent randomized clinical trial (the Further Cardiovascular Outcomes Research with Proprotein convertase subtilisin/kexin type 9 (PCSK9) Inhibition in Subjects with Elevated Risk Trial) using data collected from 2013 to 2016, from 1242 centers in 49 countries including Korea, reported that the $\mathrm{LDL}_{\text {Martin }}$ equation more closely approximated the gold-standard preparative ultracentrifugation values than did $\mathrm{LDL}_{\text {Friedewald }}$ [3]. In the present study, $\mathrm{LDL}_{\mathrm{Martin}}$ showed good agreement with $\mathrm{LDL}_{\text {direct }}$ $(\mathrm{ICC}=0.92)$, with mean systemic differences from -11.1 to $5.7 \%(-12.5$ to $4.4 \mathrm{mg} / \mathrm{dL})$ in the three populations. 
In the subgroup analysis, $\mathrm{LDL}_{\mathrm{Martin}}$ was in the top three equations for estimated LDL in both subgroups $\left(\mathrm{LDL}_{\mathrm{dir}}\right.$ ect $<70 \mathrm{mg} / \mathrm{dL}$ or $\geq 70 \mathrm{mg} / \mathrm{dL}$, Supplementary Tables S3 and S4). In subgroups of TG, $\mathrm{LDL}_{\text {Martin }}$ was in the top three equations for estimated LDL (TG group 2 with $175-400 \mathrm{mg} / \mathrm{dL}$ and TG group 3 with $>400 \mathrm{mg} / \mathrm{dL}$ ), except for TG group 1 patients whose $\mathrm{TG}<175 \mathrm{mg} / \mathrm{dL}$. In patients with $\mathrm{TG}<175 \mathrm{mg} / \mathrm{dL}, \mathrm{LDL}_{\mathrm{Choi}}, \mathrm{LDL}_{\mathrm{Vujovic}}$, and $\mathrm{LDL}_{\text {deLong }}$ frequently were listed in the top three equations (Supplementary Tables S5 and S6). Previous studies about $\mathrm{LDL}_{\text {cal }}$ have been performed in various ethnic cohorts with different characteristics, such as range of lipid concentrations and measurement methods for $\mathrm{LDL}_{\text {direct }}$ (Table 2). All equations compared in this study varied in design factors, such as target population or specific characteristics, by developer. Because of this, equation comparisons should be interpreted carefully. In the present study, $\mathrm{LDL}_{\mathrm{cal}}$ using $\mathrm{LDL}_{\mathrm{Hattori}}$ showed a very high result in population 3 (KNHANES 2017, Validation cohort 2). Meanwhile, as in Supplementary Tables S1 to S6 and Figs. 2 and 3, $\mathrm{LDL}_{\mathrm{Ahmadi}}$ was different from the other equations. Each of the 12 equations for $\mathrm{LDL}_{\text {cal }}$ reflected a different effect of TG in the population data used. Equations of $\mathrm{LDL}_{\text {Hattori }}$ and $\mathrm{LDL}_{\mathrm{Ahmadi}}$ were designed using subjects with $\mathrm{TG} \leq 400 \mathrm{mg} / \mathrm{dL}$ and $\mathrm{TG}<$ $100 \mathrm{mg} / \mathrm{dL}$, respectively. While $\mathrm{LDL}_{\text {Vujovic }}$ was also from subjects with $\mathrm{TG} \leq 400 \mathrm{mg} / \mathrm{dL}$, it was based on $\mathrm{LDL}_{\text {direct }}$ values measured using an automated enzymatic method.

Table 2 Characteristics of the 12 equations for calculated LDL

\begin{tabular}{|c|c|c|c|c|c|c|c|}
\hline $\mathrm{LDL}_{\text {cal }}$ & $\begin{array}{l}\text { Pub. } \\
\text { year }\end{array}$ & $\begin{array}{l}\mathrm{N} \text { of subjects } \\
\text { or specimens }\end{array}$ & $\begin{array}{l}\text { Studied } \\
\text { region }\end{array}$ & $\begin{array}{l}\text { Specimen } \\
\text { type }\end{array}$ & TG concentration characteristics & $\begin{array}{l}\text { Measurement } \\
\text { method for LDL } \\
\text { quantification }\end{array}$ & Equations \\
\hline $\mathrm{LDL}_{\text {Friedwald }}$ & 1972 & 448 subjects & USA & Plasma & TG ranged $20-2502$ mg/dL. & Ultracentrifugation & $\mathrm{TC}-\mathrm{HDL}-(\mathrm{TG} / 5)$ \\
\hline LDL DeLong & 1986 & 10,483 subjects & USA & $\begin{array}{l}\text { Plasma or } \\
\text { serum }\end{array}$ & $\begin{array}{l}964 \text { subjects whose TG > } \\
400 \text { mg/dL were included. }\end{array}$ & Ultracentrifugation & $\mathrm{TC}-(\mathrm{HDL}+0.16 \times \mathrm{TG})$ \\
\hline $\mathrm{LDL}_{\text {Rao }}$ & 1988 & 196 sera & Kuwait & Serum & $\begin{array}{l}33 \text { subjects defined as high } \\
\text { TG (> } 204 \mathrm{mg} / \mathrm{dL}) \text { were } \\
\text { included. }\end{array}$ & Ultracentrifugation & $\begin{array}{l}\mathrm{TC}-\mathrm{HDL}-\{\mathrm{TG} \times[0.203- \\
(0.00011 \times \mathrm{TG})]\}\end{array}$ \\
\hline $\mathrm{LDL}_{\text {Hattori }}$ & 1998 & 2179 subjects & Japan & Plasma & $\begin{array}{l}\text { Subjects with TG }>400 \mathrm{mg} / \mathrm{dL} \\
\text { were excluded. }{ }^{\text {a }}\end{array}$ & Ultracentrifugation & $\begin{array}{l}(0.94 \times \mathrm{TC})-(0.94 \times \mathrm{HDL}) \\
-0.19 \times \mathrm{TG}\end{array}$ \\
\hline $\mathrm{LDL}_{\text {Anadaraja }}$ & 2005 & 2008 subjects & India & Plasma & $\begin{array}{l}153 \text { subjects whose TG > } \\
350 \mathrm{mg} / \mathrm{dL} \text { were included. }\end{array}$ & Ultracentrifugation & $\begin{array}{l}(0.9 \times \mathrm{TC})-(0.9 \times \mathrm{TG} / 5)- \\
28\end{array}$ \\
\hline $\mathrm{LDL}_{\text {Ahmadi }}$ & 2008 & $\begin{array}{l}230 \text { sera from } \\
115 \text { subjects }\end{array}$ & Iran & Serum & $\begin{array}{l}\text { All subjects had TG }<350 \mathrm{mg} / \mathrm{dL} \text {. }^{\text {a }} \\
\text { Equations were produced using } \\
\text { data from patients with } \\
\mathrm{TG}<100 \mathrm{mg} / \mathrm{dL} \text {. }\end{array}$ & $\begin{array}{l}\text { Automated } \\
\text { enzymatic } \\
\text { method }\end{array}$ & $\begin{array}{l}(\mathrm{TC} / 1.19)-(\mathrm{HDL} / \\
1.1)+(\mathrm{TG} / 1.9)-38\end{array}$ \\
\hline $\mathrm{LDL}_{\text {Puavilai }}$ & 2009 & 999 sera & Thailand & Serum & $\begin{array}{l}80 \text { subjects whose TG > } \\
300 \text { mg/dL were included. }\end{array}$ & $\begin{array}{l}\text { Automated } \\
\text { enzymatic } \\
\text { method }\end{array}$ & $\mathrm{TC}-\mathrm{HDL}-(\mathrm{TG} / 6)$ \\
\hline $\mathrm{LDL}_{\text {Vujovic }}$ & 2010 & 2053 subjects & Serbia & Serum & $\begin{array}{l}\text { Subjects with TG }>400 \mathrm{mg} / \mathrm{dL} \\
\text { were excluded. }^{\text {a }}\end{array}$ & $\begin{array}{l}\text { Automated } \\
\text { enzymatic } \\
\text { method }\end{array}$ & $\mathrm{TC}-\mathrm{HDL}-(\mathrm{TG} / 6.58)$ \\
\hline $\begin{array}{l}\mathrm{LDL}_{\text {Chen }} \\
\text { and Zhang }\end{array}$ & 2010 & 2180 subjects & China & Serum & $\begin{array}{l}480 \text { subjects whose } \mathrm{TG}>400 \mathrm{mg} / \mathrm{dL} \\
\text { were included. }\end{array}$ & $\begin{array}{l}\text { Automated } \\
\text { enzymatic } \\
\text { method }\end{array}$ & $\begin{array}{l}(\mathrm{TC}-\mathrm{HDL}) \times 0.9-(\mathrm{TG} \times \\
0.1)\end{array}$ \\
\hline $\begin{array}{l}L D L_{\text {de }} \\
\text { Cordova }\end{array}$ & 2013 & 10,664 subjects & Brazil & Serum & $\begin{array}{l}470 \text { subjects whose } \mathrm{TG}>400 \mathrm{mg} / \mathrm{dL} \\
\text { were included. }\end{array}$ & $\begin{array}{l}\text { Automated } \\
\text { enzymatic } \\
\text { method }\end{array}$ & $0.7516 \times(T C-H D L)$ \\
\hline $\mathrm{LDL}_{\text {Martin }}$ & 2013 & $1,350,908$ subjects & USA & Serum & $\begin{array}{l}\text { 10,124 subjects whose } \\
\mathrm{TG}>400 \mathrm{mg} / \mathrm{dL} \text { were included. }\end{array}$ & Ultracentrifugation & $\begin{array}{l}\text { (TC }-\mathrm{HDL})-(\mathrm{TG} / \\
\text { different adjustable factors) }\end{array}$ \\
\hline $\mathrm{LDL}_{\text {Choi }}$ & $\begin{array}{l}\text { This } \\
\text { study }\end{array}$ & $\begin{array}{l}\text { Development cohort: } 5198 \\
\text { sera from } 4562 \text { subjects } \\
\text { Validation cohort 1: } 2163 \\
\text { sera from } 2086 \text { subjects } \\
\text { Validation cohort } 2: 889 \\
\text { sera from } 889 \text { subjects }\end{array}$ & $\begin{array}{l}\text { South } \\
\text { Korea }\end{array}$ & Serum & $\begin{array}{l}302 \text { sera with } \mathrm{TG}>400 \mathrm{mg} / \mathrm{dL} \text { were } \\
\text { included. } \\
75 \text { sera with } \mathrm{TG}>400 \mathrm{mg} / \mathrm{dL} \text { were } \\
\text { included. } \\
\text { All subjects had TG } \geq 200 \mathrm{mg} / \mathrm{dL} \\
\text { (Among them, } 131 \text { had } \\
\text { TG }>400 \mathrm{mg} / \mathrm{dL} \text { ) }\end{array}$ & $\begin{array}{l}\text { Automated } \\
\text { enzymatic } \\
\text { method }^{b}\end{array}$ & $\begin{array}{l}\mathrm{TC}-0.87 \times \mathrm{HDL}-0.13 \times \\
\mathrm{TG}\end{array}$ \\
\hline
\end{tabular}

HDL high-density lipoprotein, LDL low-density lipoprotein, Pub. publication, TC total cholesterol, TG triglycerides

Equation of $L D L_{\text {Puavilai }}$ was similar with that of $\mathrm{LDL}_{\text {DeLong. }} \mathrm{LDL}$ de Cordova does not include $\mathrm{TG}$ concentration

${ }^{\text {a }}$ These equations did not include data from patients whose TG $>400 \mathrm{mg} / \mathrm{dL}$

${ }^{b}$ Automated c702 analyzers using LDL-cholesterol plus 2nd generation reagent for the development cohort and LDL-cholesterol 3rd generation reagent for the validation cohort 1 were used (Cobas 8000 c702, Roche, Germany). For validation cohort 2, Hitachi 7600-210 (Hitachi, Tokyo, Japan) analyzer using Cholestest LDL reagent (Sekisui Medical, Tokyo, Japan) was used 
Various measurement methods of lipids can vary in accuracy, convenience, and cost [15]. Considering that current clinical laboratories usually determine $\mathrm{LDL}_{\text {direct }}$ by automatic enzymatic methods and physicians manage patients with strategies based on these values from clinical laboratories, $\mathrm{LDL}_{\mathrm{cal}}$ obtained from $\mathrm{LDL}_{\text {direct }}$ calculated by automatic enzymatic methods might better classify patients at risk [28]. Future studies are needed to define the accuracy and clinical impacts of various equations in large numbers of populations.

\section{Strengths and limitations}

The strengths of this study are development of a new calculation equation ( $\mathrm{LDL}_{\mathrm{Choi}}$ ) using a relatively large number of Korean subjects and for which accuracy were compared with that of multiple other equations. Furthermore, calculators for the 12 equations are provided as an online supplementary material and can help physicians and researchers validate $\mathrm{LDL}_{\mathrm{cal}}$ in different ethnic populations. The limitations of this study are the retrospective design and the lack of clinical information including detailed history and physical examination and other laboratory and image studies associated with cardiovascular and other diseases, which is out of the scope of this study. The results of this study might not be generalizable to other populations as all data were from Korean adults. To enhance generalizability, future studies using different ethnic populations and ages are needed. Future studies on the clinical impact of the practice using large numbers of patients with various $\mathrm{LDL}_{\text {cal }}$ and $\mathrm{LDL}_{\text {direct }}$ in various ethnicities are needed.

\section{Conclusions}

In conclusion, a new $\mathrm{LDL}_{\text {Choi }}$ equation for estimated $\mathrm{LDL}_{\text {cal }}$ was developed and validated in a Korean population and compared with 11 previous equations using $\mathrm{LDL}_{\text {direct }}$ as a reference method. The accuracy of $\mathrm{LDL}_{\text {Choi }}$ was highest in laboratory-specific populations. Considering that the accuracy varied according to cohort (population), $\mathrm{LDL}_{\text {direct, }}$ and $\mathrm{TG}$ concentration, direct measurement of LDL is needed for accurate evaluation of LDL. This study can help to expand our knowledge about $\mathrm{LDL}_{\text {cal }}$ in Korean populations and to improve test utilization.

\footnotetext{
Abbreviations

ATP III: Adult treatment panel III; HDL: High-density lipoprotein cholesterol; ICC: Intraclass correlation coefficient; IRB: Institutional review board; KNHA NES: Korea national health and nutrition examination survey; LDL: Lowdensity lipoprotein cholesterol; LDL $L_{\text {Ahmadi: }}$ Low-density lipoprotein cholesterol calculation using equation by Ahmadi et al.; $\mathrm{LDL}_{\text {Anandaraja: }}$ Lowdensity lipoprotein cholesterol calculation using equation by Anandaraja et al.; $\mathrm{LDL}_{\mathrm{cal}}$ : Low-density lipoprotein cholesterol calculation; $\mathrm{LDL}_{\mathrm{Chen} \text { and }}$ Zhang: Low-density lipoprotein cholesterol calculation using equation by Chen and Zhang et al.; LDL $L_{\text {Choi: }}$ Low-density lipoprotein cholesterol calculation using a new equation by Choi et al.; LDLde Cordova: Low-density lipoprotein cholesterol calculation using equation by de Cordova et al.;
}

LDLDeLong: Low-density lipoprotein cholesterol calculation using equation by DeLong et al.; LDLdirect: Directly measured low-density lipoprotein cholesterol; LDLFriedewald: Low-density lipoprotein cholesterol calculation using equation by Friedewald et al.; LDL $L_{\text {Hattori: }}$ Low-density lipoprotein cholesterol calculation using equation by Hattori et al.; $L D L_{\text {Martin: }}$ Low-density lipoprotein cholesterol calculation using equation by Martin et al.; LDLpuavila: Low-density lipoprotein cholesterol calculation using equation by Puavilai et al.; LDL $L_{\text {RaO }}$ : Low-density lipoprotein cholesterol calculation using equation by Rao et al.; LDLvujovic: Low-density lipoprotein cholesterol calculation using equation by Vujovic et al.; NCEP: National cholesterol education program; PCSK9: Proprotein convertase subtilisin/kexin type 9; TC: Total cholesterol; TG: Triglycerides; VLDL: Very-low-density lipoprotein cholesterol; VOYAGER: indiVidual patient meta-analysis Of statin therapY in At risk Groups: Effects of Rosuvastatin, atorvastatin and simvastatin

\section{Supplementary Information}

The online version contains supplementary material available at https://doi. org/10.1186/s12944-021-01525-6.

\section{Additional file 1: Supplementary Material S1. $L D L$ calculators for the} 12 equations.

Additional file 2: Supplementary Table S1. Intraclass correlation coefficient and systemic differences among the 12 equations in comparison with directly measured LDL. Supplementary Table S2. Limits of agreement and absolute error among the 12 equations in comparison with directly measured LDL. Supplementary Table S3. Intraclass correlation coefficient and systemic differences among the 12 equations in comparison with directly measured $L D L\left(L D L_{\text {direct }}\right)$ by subgroup of LDL concentration. Supplementary Table S4. Limits of agreement and absolute error among the 12 equations in comparison with directly measured LDL by subgroup of LDL concentration.

Supplementary Table S5. Intraclass correlation coefficient and systemic differences among the 12 equations in comparison with directly measured LDL according to subgroup by triglyceride (TG) concentration. Supplementary Table S6. Limit of agreement and absolute percentage errors among the 12 equations in comparison with directly measured LDL according to subgroups by triglyceride (TG) concentration.

Supplementary Fig. S1. Bland-Altman plots for the 12 equations with directly measured LDL concentration. Supplementary Fig. S2. Overall agreement of categorization according to the NCEP ATP III between calculated LDL and directly measured LDL by LDL subgroup.

Supplementary Fig. S3. Overall agreement of categorization according to the NCEP ATP III between calculated LDL and directly measured LDL by TG subgroup.

\section{Acknowledgments}

Thanks to Ms. Hyunjoo Son and Ms. Jiseon Kim at Green Cross Laboratories for their administrative support.

\section{Authors' contributions}

This work was performed as collaboration among all the authors. All the authors have accepted responsibility for the entire content of this submitted manuscript and approved submission. Conceptualization: Rihwa Choi, Sang Gon Lee; Data Curation: Rihwa Choi, Mi-Jung Park, Youngju Oh, Sung Ho Kim; Formal Analysis: Rihwa Choi; Funding Acquisition: Sang Gon Lee and Eun Hee Lee; Investigation: Rihwa Choi, Sang Gon Lee; Methodology: Rihwa Choi, Sang Gon Lee; Project Administration: Rihwa Choi, Youngju Oh; Resources: Rihwa Choi, Youngju Oh, Sang Gon Lee; Software: Rihwa Choi, Sung Ho Kim; Supervision: Sang Gon Lee, Eun Hee Lee; Validation: Rihwa Choi, Sang Gon Lee; Visualization: Rihwa Choi; Writing - Original Draft Preparation: Rihwa Choi; Writing - Review \& Editing: Rihwa Choi, Mi-Jung Park, Youngju Oh, Sung Ho Kim, Sang Gon Lee and Eun Hee Lee.

\section{Funding}

This research did not receive any specific grant from funding agencies in the public, commercial, or not-for-profit sectors. 


\section{Availability of data and materials}

The datasets used and analyzed during the current study are available from the corresponding authors on reasonable request.

\section{Declarations}

\section{Ethics approval and consent to participate}

This study was conducted according to the Declaration of Helsinki guidelines, and all procedures involving human subjects were approved by the Institutional Review Board (IRB) of Green Cross Laboratories (GCL-20191001-01). A waiver of informed consent was approved by the IRB since the waiver would not adversely affect the rights and welfare of the subjects because the study was retrospective and involved no more than minimal risk to the subjects.

\section{Consent for publication}

Not applicable.

\section{Competing interests}

No potential conflicts of interest relevant to this article were reported.

\section{Author details}

${ }^{1}$ Department of Laboratory Medicine, Green Cross Laboratories, 107, Ihyeonro 30 beon-gil, Giheng-gu, Yongin-Si, Gyeonggi-do, Republic of Korea. ${ }^{2}$ Department of Laboratory Medicine and Genetics, Samsung Medical Center, Sungkyunkwan University School of Medicine, Gangnam-gu, Seoul, Republic of Korea.

Received: 2 June 2021 Accepted: 16 August 2021

Published online: 20 September 2021

\section{References}

1. Langlois MR, Chapman MJ, Cobbaert C, Mora S, Remaley AT, Ros E, et al. Quantifying Atherogenic lipoproteins: current and future challenges in the era of personalized medicine and very low concentrations of LDL cholesterol. A consensus Statement from EAS and EFLM. Clin Chem. 2018; 64(7):1006-33. https://doi.org/10.1373/clinchem.2018.287037.

2. Gragnano F, Calabrò P. Role of dual lipid-lowering therapy in coronary atherosclerosis regression: evidence from recent studies. Atherosclerosis. 2018;269:219-28. https://doi.org/10.1016/j.atherosclerosis.2018.01.012.

3. Martin SS, Giugliano RP, Murphy SA, Wasserman SM, Stein EA, Ceska R, et al. Comparison of low-density lipoprotein cholesterol assessment by Martin/ Hopkins estimation, Friedewald estimation, and preparative ultracentrifugation: insights from the FOURIER trial. JAMA Cardiol. 2018;3(8): 749-53. https://doi.org/10.1001/jamacardio.2018.1533.

4. Martin SS, Blaha MJ, Elshazly MB, Toth PP, Kwiterovich PO, Blumenthal RS, et al. Comparison of a novel method vs the Friedewald equation for estimating low-density lipoprotein cholesterol levels from the standard lipid profile. Jama. 2013;310(19):2061-8. https://doi.org/10.1001/jama.2013.280532.

5. Miller WG, Myers GL, Sakurabayashi I, Bachmann LM, Caudill SP, Dziekonski A, et al. Seven direct methods for measuring HDL and LDL cholesterol compared with ultracentrifugation reference measurement procedures. Clin Chem. 2010;56(6):977-86. https://doi.org/10.1373/clinchem.2009.142810.

6. Korzun WJ, Nilsson G, Bachmann LM, Myers GL, Sakurabayashi I, Nakajima K, et al. Difference in bias approach for commutability assessment: application to frozen pools of human serum measured by 8 direct methods for HDL and LDL cholesterol. Clin Chem. 2015;61(8):1107-13. https://doi.org/10.1373/ clinchem.2015.240861.

7. Bachorik PS, Ross JW, National Cholesterol Education Program recommendations for measurement of low-density lipoprotein cholesterol: executive summary. The National Cholesterol Education Program Working Group on lipoprotein measurement. Clin Chem. 1995;41(10):1414-20. https://doi.org/10.1093/clinchem/41.10.1414.

8. Rim JH, Lee YH, Lee MH, Kim HY, Choi J, Lee BW, et al. Comparison and validation of 10 equations including a novel method for estimation of LDLcholesterol in a 168,212 Asian population. Medicine (Baltimore). 2016;95(14): e3230. https://doi.org/10.1097/MD.0000000000003230.

9. Friedewald WT, Levy RI, Fredrickson DS. Estimation of the concentration of low-density lipoprotein cholesterol in plasma, without use of the preparative ultracentrifuge. Clin Chem. 1972;18(6):499-502. https://doi.org/1 0.1093/clinchem/18.6.499.
10. Miller M, Stone NJ, Ballantyne C, Bittner V, Criqui MH, Ginsberg HN, et al Triglycerides and cardiovascular disease: a scientific statement from the American Heart Association. Circulation. 2011;123(20):2292-333. https://doi. org/10.1161/CIR.0b013e3182160726.

11. Puavilai W, Laorugpongse D, Deerochanawong C, Muthapongthavorn N, Srilert $P$. The accuracy in using modified Friedewald equation to calculate LDL from non-fast triglyceride: a pilot study. J Med Assoc Thail. 2009;92(2): 182-7. 19253792.

12. Teerakanchana T, Puavilai W, Suriyaprom K, Tungtrongchitr R. Comparative study of LDL-cholesterol levels in Thai patients by the direct method and using the Friedewald formula. Southeast Asian J Trop Med Public Health. 2007;38(3):519-27. 17877229.

13. Palmer MK, Barter PJ, Lundman P, Nicholls SJ, Toth PP, Karlson BW. Comparing a novel equation for calculating low-density lipoprotein cholesterol with the Friedewald equation: a VOYAGER analysis. Clin Biochem. 2019;64:24-9. https://doi.org/10.1016/j.clinbiochem.2018.10.011.

14. Choi H, Shim JS, Lee MH, Yoon YM, Choi DP, Kim HC. Comparison of formulas for calculating low-density lipoprotein cholesterol in general population and high-risk patients with cardiovascular disease. Korean Circ J. 2016;46(5):688-98. https://doi.org/10.4070/kcj.2016.46.5.688.

15. DeLong DM, DeLong ER, Wood PD, Lippel K, Rifkind BM. A comparison of methods for the estimation of plasma low- and very low-density lipoprotein cholesterol. The lipid research clinics prevalence study. JAMA. 1986;256(17): 2372-7. https://doi.org/10.1001/jama.1986.03380170088024.

16. Hattori Y, Suzuki M, Tsushima M, Yoshida M, Tokunaga Y, Wang Y, et al. Development of approximate formula for $L D L$-chol, $L D L$-apo $B$ and $L D L$ chol/LDL-apo $B$ as indices of hyperapobetalipoproteinemia and small dense LDL. Atherosclerosis. 1998;138(2):289-99. https://doi.org/10.1016/S0021-91 50(98)00034-3.

17. Anandaraja S, Narang R, Godeswar R, Laksmy R, Talwar KK. Low-density lipoprotein cholesterol estimation by a new formula in Indian population. Int J Cardiol. 2005;102(1):117-20. https://doi.org/10.1016/j.ijcard.2004.05.009.

18. Kang M, Kim J, Lee SY, Kim K, Yoon J, Ki H. Martin's equation as the Most suitable method for estimation of low-density lipoprotein cholesterol levels in Korean adults. Korean J Fam Med. 2017;38(5):263-9. https://doi.org/10.4 082/kjfm.2017.38.5.263.

19. Chen $Y$, Zhang $X$, Pan B, Jin X, Yao H, Chen B, et al. A modified formula for calculating low-density lipoprotein cholesterol values. Lipids Health Dis. 2010;9(1):52. https://doi.org/10.1186/1476-511X-9-52.

20. Petridou E, Anagnostopoulos K. Validation of the novel Martin method for LDL cholesterol estimation. Clin Chim Acta. 2019;496:68-75. https://doi.org/1 0.1016/j.cca.2019.06.023

21. Lee J, Jang S, Son H. Validation of the Martin method for estimating lowdensity lipoprotein cholesterol levels in Korean adults: findings from the Korea National Health and nutrition examination survey, 2009-2011. PLoS One. 2016;11(1):e0148147. https://doi.org/10.1371/journal.pone.0148147.

22. Nicholls SJ, Brandrup-Wognsen G, Palmer M, Barter PJ. Meta-analysis of comparative efficacy of increasing dose of atorvastatin versus Rosuvastatin versus simvastatin on lowering levels of atherogenic lipids (from VOYAGER). Am J Cardiol. 2010;105(1):69-76. https://doi.org/10.101 6/j.amjcard.2009.08.651.

23. Kuchenbaecker K, Telkar N, Reiker T, Walters RG, Lin K, Eriksson A, et al. The transferability of lipid loci across African, Asian and European cohorts. Nat Commun. 2019;10(1):4330. https://doi.org/10.1038/s41467-019-12026-7.

24. Cho KH, Park HJ, Kim JR. Decrease in serum HDL-C level is associated with elevation of blood pressure: correlation analysis from the Korean National Health and nutrition examination survey 2017. Int J Environ Res Public Health. 2020;17(3):1101. https://doi.org/10.3390/ijerph17031101.

25. Vesper HW, Wilson PW, Rifai N. A message from the laboratory community to the National Cholesterol Education Program Adult Treatment Panel IV. Clin Chem. 2012;58(3):523-7. https://doi.org/10.1373/clinchem.2011.178202.

26. Rao A. Parker AH, el-Sheroni NA, Babelly MM: calculation of low-density lipoprotein cholesterol with use of triglyceride/cholesterol ratios in lipoproteins compared with other calculation methods. Clin Chem. 1988; 34(12):2532-4. https://doi.org/10.1093/clinchem/34.12.2532.

27. Ahmadi SA, Boroumand MA, Gohari-Moghaddam K, Tajik P, Dibaj SM. The impact of low serum triglyceride on LDL-cholesterol estimation. Arch Iran Med. 2008;11(3):318-21 (PMID:18426324).

28. Vujovic A, Kotur-Stevuljevic J, Spasic S, Bujisic N, Martinovic J, Vujovic M, et al. Evaluation of different formulas for LDL-C calculation. Lipids Health Dis. 2010;9(1):27. https://doi.org/10.1186/1476-511X-9-27. 
29. de Cordova CM, de Cordova MM. A new accurate, simple formula for LDLcholesterol estimation based on directly measured blood lipids from a large cohort. Ann Clin Biochem. 2013;50(1):13-9. https://doi.org/10.1258/acb.2012. 011259.

30. Third Report of the National Cholesterol Education Program (NCEP) Expert Panel on Detection, Evaluation, and Treatment of High Blood Cholesterol in Adults (Adult Treatment Panel III) final report. Circulation. 2002;106(25): 3143-421. https://doi.org/10.1161/circ.106.25.3143.

31. Sung KC, Kwon CH, Lee MY, Kwon MJ, Lee JH, Jung MH, et al. Comparison of Low-Density Lipoprotein Cholesterol Concentrations by Direct Measurement and by Friedewald Calculation. Am J Cardiol. 2020;125(6):86673. https://doi.org/10.1016/j.amjcard.2019.12.036.

32. Mora S, Rifai N, Buring JE, Ridker PM. Comparison of LDL cholesterol concentrations by Friedewald calculation and direct measurement in relation to cardiovascular events in 27,331 women. Clin Chem. 2009;55(5): 888-94. https://doi.org/10.1373/clinchem.2008.117929.

\section{Publisher's Note}

Springer Nature remains neutral with regard to jurisdictional claims in published maps and institutional affiliations.

Ready to submit your research? Choose BMC and benefit from:

- fast, convenient online submission

- thorough peer review by experienced researchers in your field

- rapid publication on acceptance

- support for research data, including large and complex data types

- gold Open Access which fosters wider collaboration and increased citations

- maximum visibility for your research: over $100 \mathrm{M}$ website views per year

At $\mathrm{BMC}$, research is always in progress.

Learn more biomedcentral.com/submissions 